\title{
Long-term recovery from unawareness, deficient counterregulation and lack of cognitive dysfunction during hypoglycaemia, following institution of rational, intensive insulin therapy in IDDM
}

\author{
C. Fanelli ${ }^{1}$, S. Pampanelli ${ }^{1}$, L. Epifano ${ }^{1}$, A. M. Rambotti ${ }^{1}$, A. Di Vincenzo ${ }^{1}$, F. Modarelli ${ }^{1}$, M. Ciofetta ${ }^{1}$, M. Lepore ${ }^{1}$, \\ B. Annibale ${ }^{2}$, E. Torlone ${ }^{1}$, G. Perriello ${ }^{1}$, P. De Feo ${ }^{1}$, F. Santeusanio ${ }^{1}$, P. Brunetti ${ }^{1}$, G. B.Bolli ${ }^{1}$
}

${ }^{1}$ Dipartimento di Medicina Interna e Scienze Endocrine e Metaboliche, Università degli Studi di Perugia, Italy

${ }^{2}$ Cattedra di Gastroenterologia, Università La Sapienza, Rome, Italy

Summary Hypoglycaemia unawareness, is a major risk factor for severe hypoglycaemia and a contraindication to the therapeutic goal of near-normoglycaemia in IDDM. We tested two hypotheses, first, that hypoglycaemia unawareness is reversible as long as hypoglycaemia is meticulously prevented by careful intensive insulin therapy in patients with short and long IDDM duration, and that such a result can be maintained long-term. Second, that intensive insulin therapy which strictly prevents hypoglycaemia, can maintain long-term near-normoglycaemia. We studied 21 IDDM patients with hypoglycaemia unawareness and frequent mild/severe hypoglycaemia episodes while on "conventional" insulin therapy, and 20 nondiabetic control subjects. Neuroendocrine and symptom responses, and deterioration in cognitive function were assessed in a stepped hypoglycaemia clamp before, and again after 2 weeks, 3 months and 1 year of either intensive insulin therapy which meticulously prevented hypoglycaemia (based on physiologic insulin replacement and continuous education, experimental group, EXP, $n=16$ ), or maintenance of the original "conventional" therapy (control group, CON, $n=5$ ). At entry to the study, all 21 IDDM-patients had subnormal neuroendocrine and symptom responses, and less deterioration of cognitive function during hypoglycaemia. After intensive insulin therapy in EXP, the frequency of hypoglycaemia decreased from $0.5 \pm 0.05$ to $0.045 \pm 0.02$ episodes/patient-day; $\mathrm{HbA}_{1 \mathrm{c}}$ increased from $5.83 \pm 0.18$ to $6.94 \pm 0.13 \%$ (range in non-diabetic subjects 3.8-5.5\%) over a 1year period; all counterregulatory hormone and symptom responses to hypoglycaemia improved between 2 weeks and 3 months, with the exception of glucagon which improved at 1 year; and cognitive function deteriorated further as early as 2 weeks $(p<0.05)$. The improvement in responses was maintained at 1 year. The improvement in plasma adrenaline and symptom responses inversely correlated with IDDM duration. In contrast, in CON, neither frequency of hypoglycaemia, nor neuroendocrine responses to hypoglycaemia improved. Thus, meticulous prevention of hypoglycaemia by intensive insulin therapy reverses hypoglycaemia unawareness even in patients with long-term IDDM, and is compatible with long-term near-normoglycaemia. Because carefully conducted intensive insulin therapy reduces, not increases the frequency of moderate/severe hypoglycaemia, intensive insulin therapy should be extended to the majority of IDDM patients in whom it is desirable to prevent/delay the onset/progression of microvascular complications. [Diabetologia (1994) 37: 1265-1276]

Key words Autonomic neuropathy, intensive insulin therapy, hypoglycaemia unawareness, glucose counterregulation, catecholamines.
Received: 17 May 1994

and in revised form: 17 August 1994

Corresponding author: G. B. Bolli, Dipartimento di Medicina Interna e Scienze Endocrine e Metaboliche, Via E. Dal Pozzo, I-06126 Perugia, Italy

Abbreviations: IDDM, Insulin-dependent diabetes mellitus; IIT, intensive insulin therapy; HU, hypoglycaemia unawareness; EXP, experimental patient group; CON, control group
Loss of autonomic warning symptoms to impending hypoglycaemia is known as hypoglycaemia unawareness [1], a frequent syndrome in patients with insulin dependent diabetes mellitus on IDDM $[2,3]$. Unawareness of hypoglycaemia represents a major risk factor for severe hypoglycaemia (coma) in IDDM not only because unaware patients cannot recognize and correct hypoglycaemia before the onset of neuro- 
Table 1. Clinical characteristics of the subjects

\begin{tabular}{lllcc}
\hline & DDM patients & & & $\begin{array}{l}\text { Non-diabetic } \\
\text { volunteers }\end{array}$ \\
\cline { 2 - 4 } & All & Experimental Group & Control Group & 20 \\
\hline$n$ & 21 & 16 & 5 & $10 / 10$ \\
Gender (male/female) & $11 / 10$ & $8 / 8$ & $3 / 2$ & $31 \pm 3$ \\
Age (years) & $33 \pm 2$ & $32 \pm 2.7$ & $22.9 \pm 0.6$ & $23.1 \pm 0.7$ \\
BMI $\left(\mathrm{kg} / \mathrm{m}^{2}\right)$ & $22.9 \pm 0.6$ & $22.4 \pm 0.5$ & $9.2 \pm 3.4$ & - \\
Duration of diabetes (years) & $11.4 \pm 1.8$ & $12 \pm 2$ & $5.82 \pm 0.16$ & $5.1 \pm 0.11$ \\
$\mathrm{HbA}_{1 \mathrm{c}}(\%)^{\mathrm{a}}$ & $5.82 \pm 0.14$ & $5.83 \pm 0.15$ & & \\
\hline
\end{tabular}

${ }^{a}$ Range in non-diabetic subjects: $3.8-5.5 \%$

glycopenia, but also because glucose counterregulation is generally impaired $[3,4]$. At present, hypoglycaemia unawareness and impaired counterregulation represent a contraindication to the goal of near-normoglycaemia in IDDM [5-7]. Consequently, at present, patients with hypoglycaemia unawareness, often young adults, are excluded from the protective effects of therapeutic programmes of long-term nearnormoglycaemia on onset or progression of microvascular diabetic complications [8-10].

Although autonomic neuropathy [11], long diabetes duration [3], and strict glycaemic control [3, $12]$, have all been associated with hypoglycaemia unawareness, the pathogenesis of this syndrome is still unknown [1]. Recently, it was proposed that hypoglycaemia unawareness in IDDM may largely result from recurrent iatrogenic hypoglycaemia, thus creating a vicious circle [13]. Support for this hypothesis derives from studies in which reduced awareness of hypoglycaemia and counterregulatory responses have been acutely induced by single [14-16] or repeated $[17,18]$ episodes of hypoglycaemia, and from observations of large, if not full, recovery of hypoglycaemia awareness, after curing recurrent hypoglycaemia in insulinoma patients $[19,20]$, and attempts to prevent iatrogenic hypoglycaemia in IDDM patients [21-23]. In a recent study [24], substantial recovery of awareness of hypoglycaemia, counterregulation and reduction of cognitive dysfunction in hypoglycaemia, was reported after a few weeks of meticulous prevention of iatrogenic hypoglycaemia in a group of patients with short IDDM duration and previous history of recurrent hypoglycaemia during intensive insulin therapy. These results support the hypothesis [13] that hypoglycaemia unawareness in IDDM is largely the result of recurrent, iatrogenic hypoglycaemia, and open the therapeutic option of reversing or preventing it unawareness as long as hypoglycaemia may be prevented in the everyday life of IDDM patients.

However, several questions from that study [24] remain open. First, can the short-term reversibility of hypoglycaemia unawareness be maintained longterm? Second, is hypoglycaemia unawareness in long-term IDDM as reversible as in short-term IDDM? Finally, is the goal of prevention of hypogly- caemia, which successfully reverses hypoglycaemia unawareness [24], compatible long-term with the glycaemic targets of intensive therapy, or rather does it result in sustained hyperglycaemia?

The present series of studies was undertaken to test the following hypotheses: 1)meticulous prevention of iatrogenic hypoglycaemia reverses hypoglycaemia unawareness in patients with diabetes of long as well as short duration; 2) successful recovery of hypoglycaemia unawareness can be maintained longterm; 3) long-term meticulous prevention of hypoglycaemia, which reverses hypoglycaemia unawareness, is compatible with the glycaemic targets of intensive insulin therapy $[8,25]$.

\section{Subjects, materials and methods}

Subjects. Institutional Review Board approval was obtained and informed consent was given by 21 patients with IDDM, and 20 age-, sex- and BMI-matched non-diabetic volunteers (Table 1). The diabetic patients were recruited from those referred to the inpatient and/or outpatient units of the Dipartimento di Medicina Interna e Scienze Endocrine e Metaboliche, University of Perugia, on the basis of the following criteria: consistent history of frequent hypoglycaemia, i.e. capillary blood glucose concentrations of less than $3 \mathrm{mmol} / \mathrm{l}$ measured by reflectometer-read chemistrips in the absence of autonomic warning symptoms for at least 6 months prior to the study; absence of clinically overt autonomic neuropathy, as judged on the basis of a standard battery of cardiovascular tests [26]. Four patients were excluded from the study because of autonomic neuropathy. Thirteen patients were on a therapeutic regimen of two daily injections of a mixture of insulin (regular and NPH insulin given at breakfast and supper), whereas eight patients were on three insulin injections a day (regular insulin at breakfast and lunch, and regular and NPH insulin at supper). Nine patients had suffered severe hypoglycaemia (coma or need for external assistance) at least once during the year prior to the study. At the time of study, 5 diabetic patients were free of any detectable diabetic complications, whereas the remaining 12 were affected by background retinopathy, but apparently no other diabetic complications (kidney, peripheral nerves, macrovessels). They had no other disease apart from diabetes, and were not taking any drugs other than insulin. All patients enrolled in this study were different from those reported in another recent study [24]. 
Study design. After a 2-week run-in period, during which the patients kept constant the model of insulin treatment, glycaemic targets, diet and life-style, and practised home blood glucose monitoring (prior to each main meal and at bed-time), the neuroendocrine and symptom responses and cognitive function were examined during a stepped hypoglycaemic clamp (see below). Afterwards, in 16 patients, the original model insulin treatment was changed into a model based on four injections per day [25], i. e. regular insulin at breakfast, lunch and supper, and intermediate-acting insulin (NPH) at bed-time. In nine patients who had late dinner, NPH was added to regular insulin $(-70 \%$ regular $/ 30 \% \mathrm{NPH})$ at lunch time to prevent late afternoon hyperglycaemia. Occasionally, 1-3 units of regular insulin were added to the bedtime NPH if the bedtime blood glucose was greater than $11 \mathrm{mmol} / \mathrm{l}$. The diet was standardized into three main meals with no snacks. The doses of insulin injected prior to each meal and at bedtime were based on the capillary blood glucose level read by a reflectometer. To prevent hypoglycaemia, the pre-meal and bed-time blood glucose target was set at approximately 7.2 $8.3 \mathrm{mmol} / \mathrm{l}$. Upon measuring blood glucose concentration, the patients telephoned up to four times per day and received counselling regarding insulin dose, size and composition of meals and life-style. The patients were re-studied after 2 weeks, 3 months, and 1 year of following this insulin strategy. Henceforth, these 16 patients will be referred to as the experimental group. De novo appearance of clinically overt autonomic neuropathy over the period of the study was excluded in the experimental group by a re-examination of the cardiovascular tests [26] at 1 year.In the remaining five IDDM patients (control group), the original model of insulin therapy was not changed, and the patients were asked to continue the therapeutic regimen they followed at entry to the study. These patients were recruited at the same time as the experimental group, and were re-examined after 2 weeks and 3 months. However, the insulin regimen of the control group was changed to that of the experimental group after 3 months for ethical reasons, because reversibility of hypoglycaemia unawareness was observed at 2 weeks and 3 months only in the experimental group. All patients measured capillary blood glucose concentrations (reflectometer) at least four times daily (prior to each insulin injection, or prior to each meal and bed-time) for the first 3 months of the study and subsequently two-four times daily. To exclude nocturnal hypoglycaemia, capillary blood glucose was measured at 03.00 hours two-three times per week.

Stepped hyperinsulinaemic-hypoglycaemic clamp. To quantify thresholds and magnitude of responses of counterregulatory hormones, symptoms and deterioration of cognitive function in diabetic patients and non-diabetic volunteers, the stepped hyperinsulinaemic-hypoglycaemic clamp was used, as previously described [27], with minor modifications [28]. The patients were admitted to the Clinical Research Center of the $\mathrm{Di}$ partimento di Medicina Interna e Scienze Endocrine e Metaboliche, University of Perugia, 21.00-21.30 hours the night prior to the study. Long-acting insulin was withdrawn in the diabetic patients for $48 \mathrm{~h}$ and they were managed by injections of regular insulin at each meal, at bed-time, and at 03.00 hours. On the day prior to the studies, the patients were maintained normoglycaemic $(-5 \mathrm{mmol} / \mathrm{l})$ by an i.v. infusion of insulin into a superficial vein above the elbow of the left arm, as previously described [29]. Non-diabetic volunteers were admitted on the morning of the studies. All subjects were studied in the fasting state, $(\sim 12-14 \mathrm{~h}$ after the last meal $)$ and remained fasted until the end of studies. Between 07.00 and 07.30 hours, a hand vein of the left arm was cannulated retrogradely and maintained in a plexiglass thermoregulated box $\left(\sim 65^{\circ} \mathrm{C}\right)$ for sampling of arterialized-venous blood. After a 60 -min equilibration period, infusion of regular insulin (diluted to $1 \mathrm{U} / \mathrm{ml}$ in $2 \mathrm{ml}$ of the subject's blood and $0.9 \% \mathrm{NaCl}$ to a final volume of $100 \mathrm{ml}$ ) was begun at the rate of $1 \mathrm{mU} \cdot \mathrm{kg}^{-1} \cdot \mathrm{min}^{-1}$ for $270 \mathrm{~min}$, followed by $2 \mathrm{mU} \cdot \mathrm{kg}^{-1} \cdot \mathrm{min}^{-1}$ for a further $90 \mathrm{~min}$, using a syringe pump (Harvard Apparatus, Ealing, South $\mathrm{Na}$ tick, Mass., USA). Plasma glucose was clamped by variable glucose infusion at sequential target glucose concentrations of $\sim 4.3,3.6,3.0$, and $2.3 \mathrm{mmol} / 1$, based on plasma glucose concentrations measured every $5 \mathrm{~min}$. Each of these steps lasted $90 \mathrm{~min}$; the first $45 \mathrm{~min}$ were used to reach the desired plateau plasma glucose concentration, and the last $45 \mathrm{~min}$ to maintain a steady-state. Arterialized venous blood samples were drawn every 15-30 min for determination of plasma free insulin, growth hormone, glucagon, cortisol, adrenaline and noradrenaline, and pancreatic polypeptide. A semiquantitative symptom questionnaire was compiled every $15 \mathrm{~min}$. Subjects scored from 0 (none) to 5 (severe) for each of the following symptoms: dizziness, tingling, blurred vision, difficulty in thinking, faintness, anxiety, palpitations, hunger, sweating, irritability, or tremor. In accordance with previous classifications $[27,28,30]$, the first five symptoms were considered to be neuroglycopaenic and the last six autonomic. The sum of each of these constituted the symptom score. In addition, at baseline and during each plateau the following standard cognitive tests were compiled: trail-making part B, verbal fluency, interference subtest from the Stroop test, simple and choice visual reaction time, word and colour subtest from the Stroop test, digit vigilance test, trail-making part A, verbal memory test and forward and backward digit span, as previously described $[27,28]$. The evening before the study, subjects extensively practiced each test. For the actual study, six alternate forms were prepared. Diabetic patients, non-diabetic subjects and the person who administered the symptom and cognitive tests were all blinded to the experimental condition.

Analytical methods. Plasma glucose was measured using a Beckman Glucose Analyzer (Beckman Instruments, Palo Alto, Calif., USA). Plasma insulin, growth hormone, cortisol, adrenaline and noradrenaline [31] and pancreatic polypeptide [32] were measured by previously described assays. To remove antibody-bound insulin, plasma was mixed with an equal volume of $30 \%$ polyethylene glycol immediately after blood collection [29]. Plasma glucagon was measured by radioimmunoassay using a commercially available kit (ICN Biomedical, Inc., Costa Mesa, Calif., USA). $\mathrm{HbA}_{1 \mathrm{c}}$ was determined by a high performance liquid chromatography method (range in non-diabetic subjects $3.8-5.5 \%$ ).

Statistical analysis. Glycaemic thresholds for a given parameter were defined as the plasma glucose concentration at which the parameter first exceeded the $95 \%$ confidence limit observed for changes in that parameter at the corresponding time point in normoglycaemic control experiments, as previously reported $[27,28,30]$. Euglycaemic control experiments were performed in 20 volunteers and 7 IDDM patients whose results did not differ from those of the non-diabetic subjects. Data are given as means \pm SEM. Because of differences in units of treatment, results of cognitive tests were transformed to zscores (individual values minus mean divided standard deviation) [33] to permit their summation to obtain one unitless value for evaluation $[27,28]$. A commercially available software package (CSS, Stasoft, Tulsa, Okla., USA) was used for statistical analysis. The differences among groups were analysed using either analysis of variance followed by the Least Significant Difference test or the chi-square test [33]. 


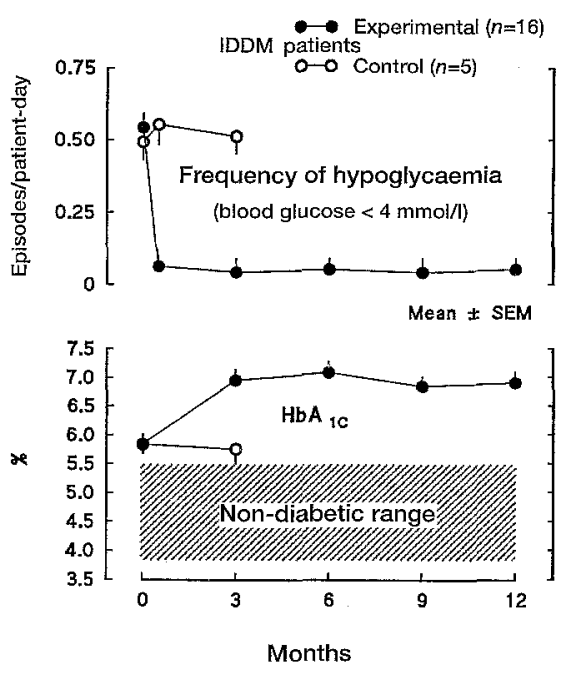

Fig. 1. Time-course of frequency of hypoglycaemia and percentage of $\mathrm{HbA}_{1 \mathrm{c}}$ in the 16 IDDM patients in whom hypoglycaemia was meticulously prevented (Experimental) and in the 5 IDDM patients in whom it was not (Control). The estimated frequency of hypoglycaemia was based on reflectometer-read capillary blood glucose concentration four times daily, i.e. prior to each main meal and at bed-time, and was defined as blood glucose $<4 \mathrm{mmol} / 1$

\section{Results}

Frequency of hypoglycaemia and percentage of glycated haemoglobin (Fig. 1). At the end of the run-in period, the frequency of hypoglycaemia (defined as capillary blood glucose concentration $<4 \mathrm{mmol} / \mathrm{l}$, reflectometer reading) in the 21 IDDM patients was $0.52 \pm 0.05$ episodes/patient-day, and the $\% \mathrm{HbA}_{1 \mathrm{c}}$ was $5.82 \pm 0.16$. Inspection of the blood glucose monitoring data, indicated that approximately $65 \%$ of the hypoglycaemic episodes occurred in the late morning in the 13 patients who injected a mixture of regular and NPH insulin at breakfast. However, in all patients approximately $40 \%$ of hypoglycaemia occurred between midnight and 02.00 hours. In the experimental group, after 2 weeks of meticulous prevention of hypoglycaemia, the frequency of hypoglycemia decreased about 10 -fold, to $0.06 \pm 0.02$ episodes/ patient-day, and remained between approximately 0.04 and 0.05 episodes/patient-day over the following 12 months. During this period, severe hypoglycaemia (coma, seizures, or need for external assistance) never occurred. The $\% \mathrm{HbA}_{1 \mathrm{c}}$ increased from $5.83 \pm 0.18$ (basal) to $6.94 \pm 0.13$ (3 months) $(p<0.05)$, and remained between 6.8 and $7.1 \%$ during the following 9 months. In contrast, in the control group, there was no decrease in the frequency of hypoglycaemia over 3 months, and no increase in the $\% \mathrm{HbA}_{1 \mathrm{c}}$ (Fig. 1).

Stepped hyperinsulinaemic-hypoglycaemic clamp at entry to the study in all IDDM patients (Fig. 2). Following insulin infusion, plasma insulin concentration

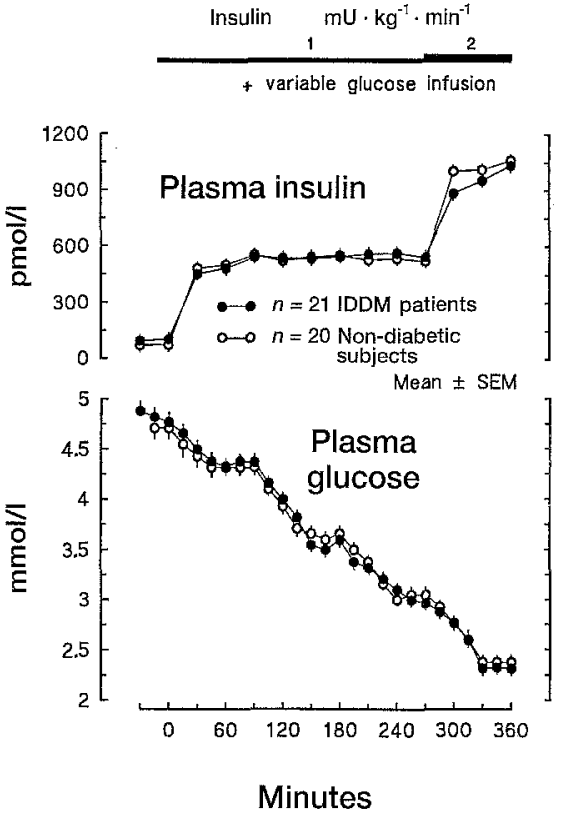

Fig. 2. Plasma insulin and glucose concentrations during the stepped hyperinsulinaemic-hypoglycaemic clamp experiments of the basal study

increased to similar values in IDDM patients and non-diabetic volunteers. In IDDM patients, plasma glucose concentration was $4.88 \pm 0.12 \mathrm{mmol} / \mathrm{l}$ at baseline, and was progressively reduced to the programmed plateau values by variable glucose infusion $(4.36 \pm 0.06 \mathrm{mmol} / 1$ between $45-90 \mathrm{~min}, 3.64 \pm$ $0.04 \mathrm{mmol} / 1$ between $135-180 \mathrm{~min}, 2.96 \pm 0.05 \mathrm{mmol} /$ 1 between $225-270 \mathrm{~min}$, and $2.33 \pm 0.08 \mathrm{mmol} / 1$ between 315-360 min). In non-diabetic volunteers, at no time was the plasma glucose concentration different from that of the IDDM patients $(p=N S)$. In IDDM patients, plasma insulin and glucose concentrations in the clamp studies repeated after 2 weeks, 3 months and 1 year, did not differ from those of the basal clamp (data not shown).

At entry to the study, all 21 IDDM patients developed autonomic symptoms at a plasma glucose concentration more than two standard deviations below normal, i.e. diabetic patients had higher glycaemic thresholds than non-diabetic volunteers. Also glycaemic thresholds of neuroendocrine responses [plasma adrenaline (but not noradrenaline), glucagon, pancreatic polypetide, growth hormone, cortisol] and neuroglycopenic symptoms were markedly increased as compared to normal, and the responses at the lowest glycaemic plateau (maximal responses) were lower than normal $(p<0.05)$. In contrast, cognitive function deteriorated less in IDDM patients than in normal subjects both in terms of threshold and magnitude of responses $(p<0.05)$ (Table 2$)$. Among the several factors tested (age, $\% \mathrm{HbA}_{1}$, duration of diabetes), only duration of diabetes correlated (inversely) with the neuroendocrine and neuroglycopenic 
Table 2. Glycaemic thresholds (plasma glucose in $\mathrm{mmol} / \mathrm{l}$ ) of neuroendocrine and symptom responses, and deterioration in cognitive function in non-diabetic volunteers $(n=20)$, and
IDDM patients of the experimental group examined at entry of study (basal), after 2 weeks, 3 months and 1 year of meticulous prevention of hypoglycaemia

\begin{tabular}{|c|c|c|c|c|c|}
\hline & \multirow{2}{*}{$\begin{array}{l}\text { Non-diabetic } \\
\text { subjects }\end{array}$} & \multicolumn{4}{|c|}{ IDDM patients } \\
\hline & & basal & 2 weeks & 3 months & 1 year \\
\hline Adrenaline & $3.6 \pm 0.05$ & $2.9 \pm 0.06^{\mathrm{a}}$ & $2.9 \pm 0.06^{\mathrm{a}}$ & $3.3 \pm 0.06^{\mathrm{a}, \mathrm{b}}$ & $3.3 \pm 0.06^{\mathrm{a}, \mathrm{b}}$ \\
\hline Glucagon & $3.6 \pm 0.04$ & none & none & $2.44 \pm 0.11^{\mathrm{a}, \mathrm{b}}$ & $2.5 \pm 0.07^{\mathrm{a}, \mathrm{b}}$ \\
\hline Pancreatic polypeptide & $3.6 \pm 0.05$ & $2.8 \pm 0.06^{a}$ & $3 \pm 0.06^{\mathrm{a}}$ & $3.3 \pm 0.06^{\mathrm{a}, \mathrm{b}}$ & $3.4 \pm 0.06^{\mathrm{a}, \mathrm{b}}$ \\
\hline Growth hormone & $3.6 \pm 0.05$ & $3 \pm 0.05^{\mathrm{a}}$ & $3.5 \pm 0.07^{b}$ & $3.7 \pm 0.06^{\mathrm{b}}$ & $3.7 \pm 0.06^{\mathrm{b}}$ \\
\hline Neuroglycopenic symptoms & $3.1 \pm 0.04$ & $2.61 \pm 0.07^{\mathrm{a}}$ & $2.8 \pm 0.07^{\mathrm{a}}$ & $3.1 \pm 0.07^{\mathrm{a}}$ & $3 \pm 0.07^{b}$ \\
\hline Cognitive dysfunction & $2.7 \pm 0.04$ & $2.4 \pm 0.7^{3}$ & $2.6 \pm 0.7^{\mathrm{b}}$ & $2.8 \pm 0.6^{\mathrm{b}}$ & $2.8 \pm 0.7^{\mathrm{b}}$ \\
\hline
\end{tabular}

${ }^{\mathrm{a}} p<0.05$ vs non-diabetic subjects; ${ }^{\mathrm{b}} p<0.05$ vs basal
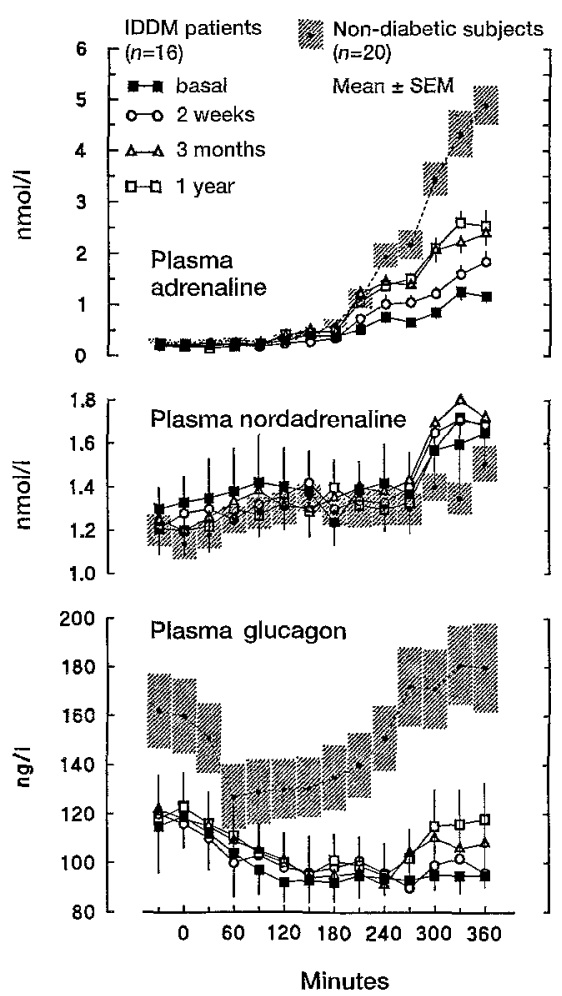

Fig. 3. Plasma adrenaline, noradrenaline and glucagon responses in the stepped hyperinsulinaemic-hypoglycaemic clamp in the non-diabetic subjects and 16 IDDM patients of the experimental group studied at entry (basal) and after 2 weeks, 3 months and 1 year of meticulous prevention of hypoglycaemia

symptom responses, and deterioration in cognitive function (all $p<0.01$ ).

\section{Experimental group}

Plasma adrenaline, noradrenaline and glucagon responses (Fig.3). In 16 IDDM patients from the experimental group, after 2 weeks of meticulous prevention of hypoglycaemia, the responses of plasma adrenaline at the lowest hypoglycaemic plateau increased $(1.56 \pm 0.15$ vs $1.09 \pm 0.12 \mathrm{nmol} / 1, p<0.05)$. At 3 months, the maximal response of plasma adrenaline increased further to $2.22 \pm 0.19 \mathrm{nmol} / 1$ ( $p<0.05 \mathrm{vs}$ basal and 2 weeks), and the glycaemic threshold also decreased (Table 2), although they did not normalize ( $p<0.05$ vs non-diabetic volunteers). At 1 year, the adrenaline responses were superimposable to those at 3 months. The responses of plasma glucagon to hypoglycaemia remained markedly suppressed after 2 weeks and 3 months of meticulous prevention of hypoglycaemia. However, at 1 year the responses of glucagon increased $(-20 \%)$ at the lowest hypoglycaemic plateau (from $95 \pm 15$ to $116 \pm 15 \mathrm{pg} / \mathrm{ml}, p<0.05$ ), and it was possible to calculate the glycaemic threshold (Table 2). The responses of plasma noradrenaline at 2 weeks, 3 months and 1 year were no different as compared to those of the basal study, nor did they differ from those of non-diabetic volunteers.

Plasma pancreatic polypeptide, growth hormone and cortisol responses (Fig.4). After 2 weeks of meticulous prevention of hypoglycaemia, the maximal responses of pancreatic polypeptide (from $51 \pm 6$ to $72 \pm 8 \mathrm{pmol} / \mathrm{l}$ ) and cortisol (from $331 \pm 28$ to $469 \pm 41$ $\mathrm{nmol} / \mathrm{l})$ increased $(p<0.05)$, and both the maximal responses and the glycaemic threshold of growth hormone normalized (Table 2). At 3 months, the maximal responses of pancreatic polypeptide and cortisol increased and their glycaemic thresholds decreased further, but only the responses of cortisol normalized fully. The responses at 1 year were superimposable to those at 3 months.

Autonomic and neuroglycopenic symptoms (Fig. 5). After 2 weeks of meticulous prevention of hypoglycaemia, the score of maximal response of autonomic symptoms increased from $2.2 \pm 0.2$ to $6.9 \pm 1$, and that of neuroglycopenic symptoms from $4.1 \pm 0.9$ to $9.7 \pm 1.1 \quad(p<0.05)$. At this time, the glycaemic 

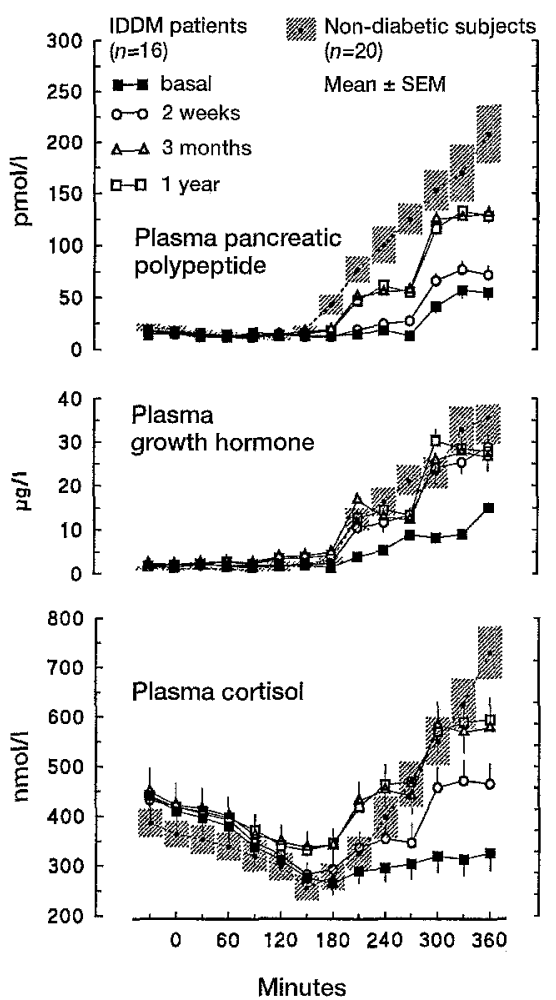

Fig.4. Plasma pancreatic polypeptide, growth hormone and cortisol responses in the stepped hyperinsulinaemic hypoglycaemic clamp in the non-diabetic subjects and 16 IDDM patients of the experimental group studied at entry (basal) and after 2 weeks, 3 months and 1 year of meticulous prevention of hypoglycaemia
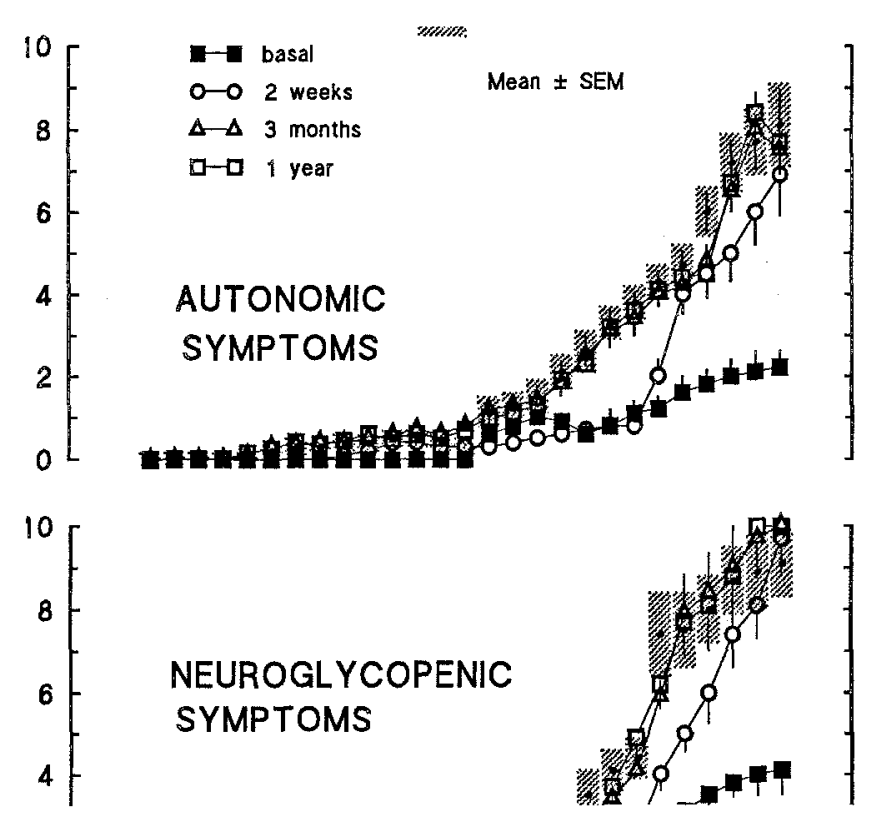

Fig. 5. Autonomic and neuroglycopenic symptom score responses in the stepped hyperinsulinaemic-hypoglycaemic clamp in the non-diabetic subjects and 16 IDDM patients of the experimental group studied at entry (basal), and after 2 weeks, 3 months and 1 year of meticulous prevention of hypoglycaemia

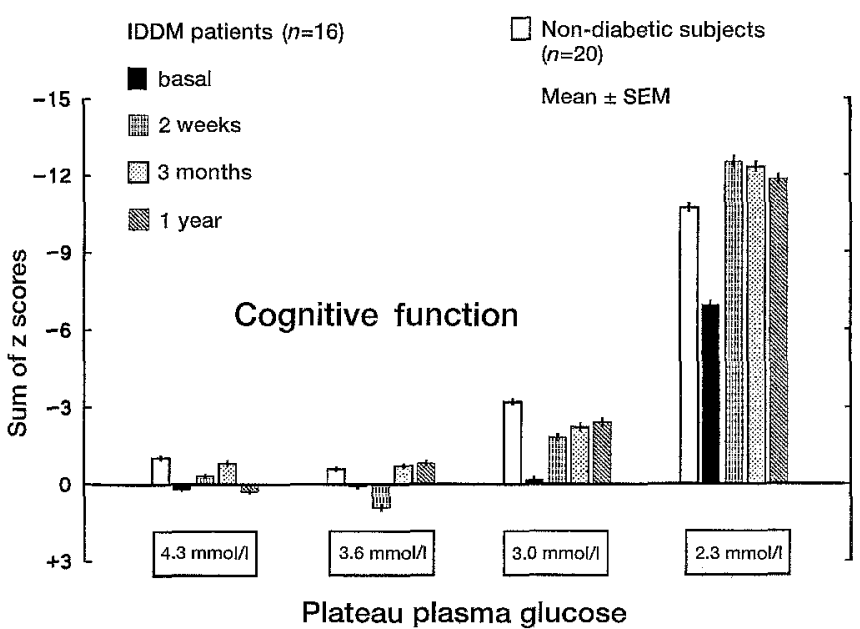

Fig. 6. Deterioration of cognitive function tests in the stepped hyperinsulinaemic hypoglycaemic clamp in the non-diabetic volunteers and 16 IDDM patients of the experimental group studied at entry (basal), and after 2 weeks, 3 months and 1 year of meticulous prevention of hypoglycaemia. Cognitive function is expressed as sum of $\mathrm{z}$ scores of single cognitive tests. Deterioration of cognitive function during hypoglycaemia in IDDM was less than in non-diabetic subjects $(p<0.05)$ at $3 \mathrm{mmol} / \mathrm{l}$ and $2.3 \mathrm{mmol} / \mathrm{l}$ plateau plasma glucose at entry (basal study), but was no longer different from non-diabetic subjects after 2 weeks, 3 months, and 1 year prevention of hypoglycaemia

threshold did not change. At 3 months, both the maximal responses and the glycaemic thresholds of autonomic and neuroglycopenic symptoms normalized (Table 2). At this time, IDDM patients again reported autonomic symptoms coinciding with episodes of blood glucose levels of less thean $3 \mathrm{mmol} / 1$ occurring in their everyday life. At 1 year, the responses were superimposable to those observed at 3 months.

Cognitive function (Fig. 6). After 2 weeks of meticulous prevention of hypoglycaemia, both the glycaemic threshold (Table 2) as well as maximal deterioration of cognitive function during hypoglycaemia (Fig. 6), normalized. The 3-month and 1-year results were superimposable to those at 2 weeks.

Rates of glucose infusion during the stepped hypoglycaemic clamp (Fig. 7). In the basal study, the rates of glucose infusion needed to maintain plasma glucose concentration at the programmed hypoglycaemic plateaus in the stepped hyperinsulinaemic-hypoglycaemic clamp, were lower in IDDM patients than in non-diabetic volunteers over the initial $180 \mathrm{~min}$ $\left(14.9 \pm 3.7\right.$ vs $\left.26 \pm 4 \mu \mathrm{mol} \cdot \mathrm{kg}^{-1} \cdot \mathrm{min}^{-1} p<0.05\right)$, but greater over the last $180 \mathrm{~min}(29.1 \pm 1.1$ vs $\left.23.1 \pm 2.2 \mu \mathrm{mol} \cdot \mathrm{kg}^{-1} \cdot \mathrm{min}^{-1}, p<0.05\right)$. After meticulous prevention of hypoglycaemia, the rates of glucose infusion over the last $180 \mathrm{~min}$ decreased in IDDM patients $(27 \pm 1.1$ and $24.8 \pm 1 \mu \mathrm{mol}$. 


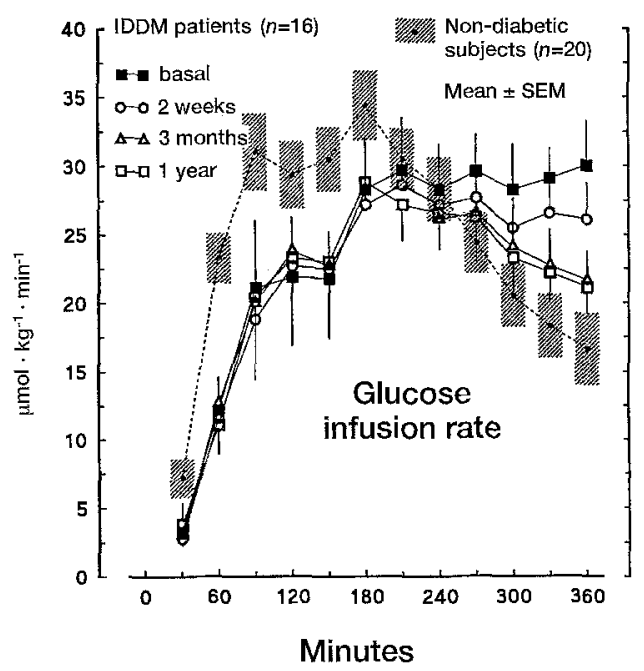

Fig. 7. Rates of glucose infusion in the stepped hyperinsulinaemic-hypoglycaemic clamp in the non-diabetic volunteers and 16 IDDM patients of the experimental group studied at entry (basal) and after 2 weeks, 3 months and 1 year of meticulous prevention of hypoglycaemia

$\mathrm{kg}^{-1} \cdot \mathrm{min}^{-1}$, at 2 weeks and 3 months, $p<0.05 \mathrm{vs}$ basal), although they remained lower than in non-diabetic volunteers $(p<0.05)$. At 1 year, the rates of glucose infusion were superimposable to those at 3 months.

Effect of diabetes duration on recovery of neuroendocrine and symptom responses and deterioration of cognitive function during hypoglycaemia (Figs. 8 and 9). Among the several factors tested (age, $\% \mathrm{HbA}_{1}$, initial impairment of responses, duration of diabetes), only duration of diabetes correlated (inversely) with the recovery of plasma adrenaline and symptom responses (Fig. 8), as well as glucagon responses (maximal responses $r=-0.55$, $p<0.01$ ) after meticulous prevention of hypoglycaemia. Patients with duration of diabetes 15 years or more had little, if any of recovery of plasma adrenaline responses as compared to patients with shorter diabetes duration (examined in terms of glycaemic thresholds and maximal responses) whereas they had recovery of symptoms similar to that of patients with diabetes duration of less than 15 years (Fig.9). Recovery of cognitive dysfunction, responses of cortisol and growth hormone to hypoglycaemia (both thresholds and maximal responses), and pancreatic polypeptide (only maximal responses, not thresholds) in patients with diabetes duration greater than 15 years were superimposable to those of patients with diabetes duration less than 15 years (Fig.9).

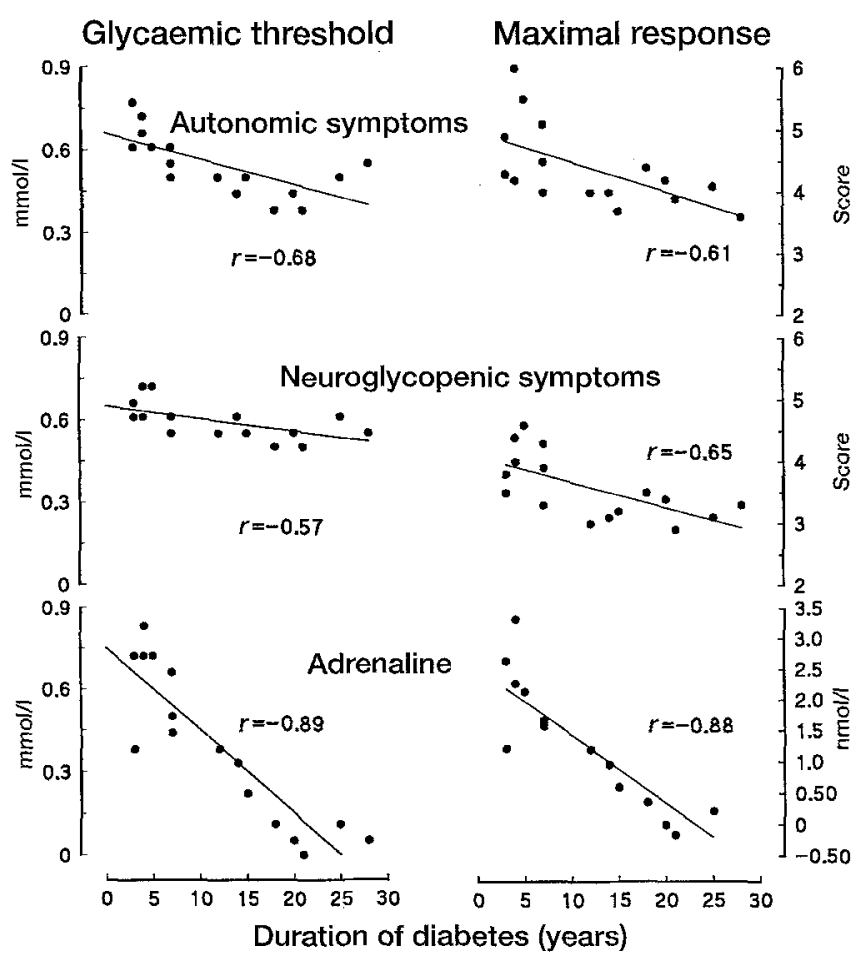

Fig. 8. Correlations between years of duration of IDDM and changes in glycaemic thresholds (left), and maximal responses (right) of autonomic and neuroglycopenic symptoms, and plasma adrenaline in the stepped hyperinsulinaemic-hypoglycaemic clamp in the 16 patients of the experimental group. The changes in glycaemic thresholds and maximal responses were calculated as difference between the plasma glucose concentration at which the response occurred after 3 months meticulous prevention of hypoglycaemia and the plasma glucose concentration of the basal study

\section{Control group (Table 3)}

When the five IDDM patients in whom no effort was made to prevent hypoglycaemia, were re-examined after 2 weeks and 3 months, the neuroendocrine and symptom responses remained suppressed, and cognitive function less deteriorated, as compared to nondiabetic volunteers, and was no different as compared to the basal study.

\section{Discussion}

First, the present studies confirm and extend the recent observation in a group of intensively treated patients with IDDM of short duration [24], i. e., meticulous prevention of hypoglycaemia largely reverses the abnormal neuroendocrine and symptom responses to hypoglycaemia also in patients with long-term IDDM under "conventional" insulin treatment with hypoglycaemia unawareness and impaired glucose counterregulation, although the results in the latter are less marked. Second, these results can be maintained long-term, and, third, are compatible long- 


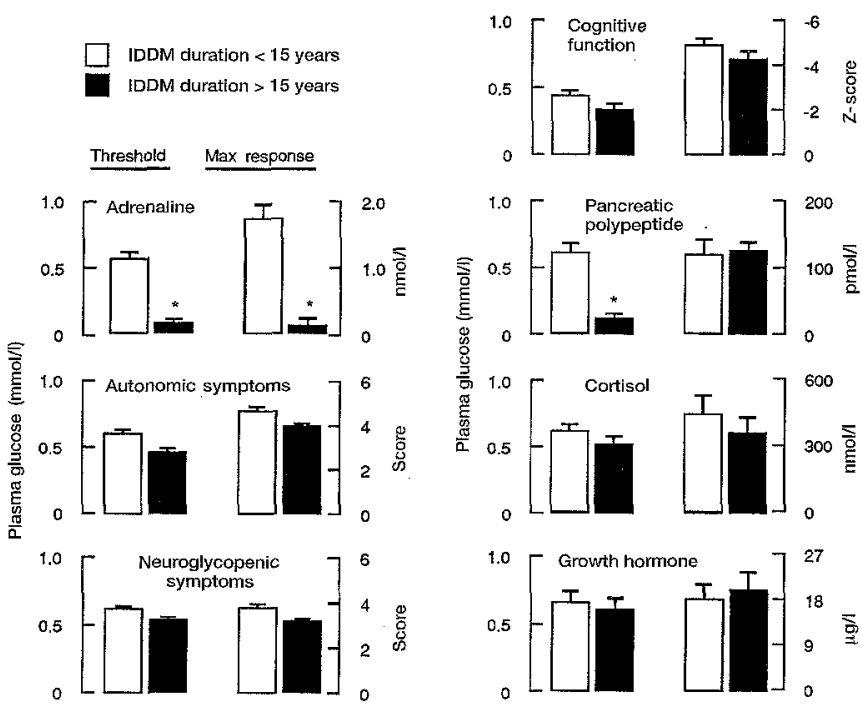

Fig.9. Recovery of neuroendocrine and symptom responses to hypoglycaemia after meticulous prevention of hypoglycaemia in IDDM patients examined at 3 months and 1 year as compared to basal, divided into patients with diabetes duration $<15$ years $(n=10,6.6 \pm 1.2$ years, A) or $\geq 15$ years $(n=6$, $21.2 \pm 1.9$ years, $Y$ ). The two columns to the left represent the decrease in glycaemic threshold of response (i.e. the difference in plasma glucose concentration at which the response first occurs after 3 months prevention of hypoglycaemia as compared to the basal study). The two columns to the right represent the increase in maximal responses after 3 months prevention of hypoglycaemia as compared to the basal study. $(* p<0.001)$

term with the glycaemic targets of intensive insulin therapy. Finally, the present studies provide additional evidence that the syndrome of hypoglycaemia unawareness is to a large extent reversible [24] as long as hypoglycaemia is meticulously prevented.

Two results of the present studies are clinically relevant: first, the long-term maintenance of recovery of hypoglycaemia unawareness is possible, even in patients with long-term IDDM. Second, the demonstration that meticulous prevention of hypoglycaemia does not result long-term in poor glycaemic control, but is compatible with maintenance of \% $\mathrm{HbA}_{1 \mathrm{c}}$ in a therapeutic range $(<7.0 \%)$ which effectively protects against appearance and/or progression of microvascular complication of diabetes [810]. In this regard, the present studies indicate that a therapeutic strategy which successfully achieves the goal of a $\% \mathrm{HbA}_{1 \mathrm{c}}$ of protection against microvascular complication without increasing the risk for hypoglycaemia, is feasible in patients with IDDM. In fact, the present studies demonstrate that, in contrast to recent reports $[8,9]$, a carefully planned and conducted intensive insulin therapy decreases, rather than increases the frequency of hypoglycaemia.

The improvement in responses to hypoglycaemia observed in these studies supports the view [13] that blunted counterregulatory hormone and symptom responses of IDDM patients with hypoglycaemia un-
Table 3. Glycaemic thresholds and maximal responses of symptoms, plasma adrenaline, pancreatic polypeptide, and deterioration of cognitive function in the five IDDM patients in whom no efforts were made to prevent hypoglycaemia (control group), at entry of study (basal), and after 2 weeks and 3 months, and in 20 non-diabetic subjects

\begin{tabular}{|c|c|c|}
\hline & $\begin{array}{l}\text { Glycaemic } \\
\text { threshold } \\
(\mathrm{mmol} / \mathrm{l})\end{array}$ & $\begin{array}{l}\text { Maximal } \\
\text { response }\end{array}$ \\
\hline \multicolumn{3}{|l|}{ Autonomics symptoms } \\
\hline IDDM basal & $2.4 \pm 0.06^{\mathrm{a}}$ & $2 \pm 0.2^{\mathrm{a}}$ score \\
\hline 2 weeks & $2.4 \pm 0.05^{a}$ & $1.9 \pm 0.15^{\mathrm{a}}$ score \\
\hline 3 months & $2.4 \pm 0.06^{\mathrm{a}}$ & $2.2 \pm 0.21^{\mathrm{a}}$ score \\
\hline Non-diabetic subjects & $3 \pm 0.7$ & $6.3 \pm 0.6$ score \\
\hline \multicolumn{3}{|c|}{ Neuroglycopenic symptoms } \\
\hline IDDM basal & $2.7 \pm 0.06^{\mathrm{a}}$ & $6.7 \pm 0.9^{\mathrm{a}}$ score \\
\hline 2 weeks & $2.6 \pm 0.05^{\mathrm{a}}$ & $6.1 \pm 0.6^{\mathrm{a}}$ score \\
\hline 3 months & $2.8 \pm 0.06^{\mathrm{a}}$ & $6.5 \pm 0.8^{\mathrm{a}}$ score \\
\hline Non-diabetic subjects & $3.1 \pm 0.05$ & $8.3 \pm 0.7$ score \\
\hline \multicolumn{3}{|l|}{ Adrenaline } \\
\hline IDDM basal & $2.9 \pm 0.06^{\mathrm{a}}$ & $1.13 \pm 0.12^{\mathrm{a}} \mathrm{nmol} / \mathrm{l}$ \\
\hline 2 weeks & $2.8 \pm 0.06^{\mathrm{a}}$ & $1.21 \pm 0.19^{\mathrm{a}} \mathrm{nmol} / 1$ \\
\hline 3 months & $2.9 \pm 0.06^{\mathrm{a}}$ & $1.09 \pm 0.2^{\mathrm{a}} \mathrm{nmol} / 1$ \\
\hline Non-diabetic subjects & $3.6 \pm 0.07$ & $4.23 \pm 0.47 \mathrm{nmol} / 1$ \\
\hline \multicolumn{3}{|l|}{ Pancreatic polypeptide } \\
\hline IDDM basal & $2.9 \pm 0.06^{\mathrm{a}}$ & $52.8 \pm 8.4^{\mathrm{a}} \mathrm{pmol} / 1$ \\
\hline 2 weeks & $2.8 \pm 0.07^{\mathrm{a}}$ & $57 \pm 11^{\mathrm{a}} \mathrm{pmol} / \mathrm{l}$ \\
\hline 3 months & $2.9 \pm 0.06^{\mathrm{a}}$ & $50 \pm 9^{a} \mathrm{pmol} / 1$ \\
\hline Non-diabetic subjects & $3.7 \pm 0.06$ & $177 \pm 20 \quad \mathrm{pmol} / 1$ \\
\hline
\end{tabular}

${ }^{a} p<0.05$ vs non-diabetic subjects

awareness, are largely secondary to recurrent therapeutic hypoglycaemia. It is likely that recurrent hypoglycaemic episodes increase the rate of glucose transport through the blood-brain barrier, and minimize neuroglycopaenia which normally occurs when plasma glucose concentration decreases below normal post-absorptive values $[27,28,30]$, as suggested by studies in rats [34] and more recently in humans [35]. Thus, minimal neuroglycopenia after recurrent hypoglycaemia reduces the hormone and symptom responses which would otherwise occur at precise glycaemic thresholds $[27,28,30,36,37]$.

The model of greater fractional extraction of glucose by the brain following recurrent hypoglycaemia [13] would predict less deterioration of brain function during hypoglycaemia due to lesser neuroglycopaenia. Some studies have not found brain protection after recurrent hypoglycaemia in patients with hypoglycaemia unawareness and IDDM [38-40] or insulinoma [19], but several others have $[3,20,24$, 41]. In a recent study [24] and in the present one, in IDDM patients with hypoglycaemia unawareness, neuroglycopenic symptoms and cognitive dysfunction initiated at lower than normal plasma glucose concentration, i.e. at higher glycaemic thresholds, and maximal responses were less than normal. This pattern reversed after prevention of hypoglycaemia. Thus, this study and others [24] support the hypo- 
thesis of an adaptation of the brain to ambient plasma glucose concentrations [13].

One might wonder why patients with hypoglycaemia unawareness are at greater risk for severe hypoglycaemia if their brain function is indeed protected from neuroglycopenia. Because of lack of early autonomic symptoms in response to an initial fall of blood glucose below normal, unaware patients do not take preventive measures (eating) to arrest progression of hypoglycaemia. Thus, blood glucose continues to fall because in these patients counterregulation is also usually impaired $[3,4$, present study]. In unaware patients, the brain tolerates the initial decrease in plasma glucose quite well because plasma glucose of approximately $2.3 \mathrm{mmol} / \mathrm{l}$ elicits virtually no deterioration of cognitive function as indicated in this and previous studies $[3,20,24]$. However, should blood glucose decrease further, neuroglycopenia might become so severe that brain function would deteriorate suddenly and result in a state of stupor and/or coma, not preceded by any symptom.

The reversibility of blunted counterregulatory hormone and symptom responses to, and greater deterioration of cognitive function during hypoglycaemia observed in these studies after meticulous prevention of hypoglycaemia is qualitatively similar to the normalization of the responses in insulinoma patients after curing hypoglycaemia by surgical removal of the tumour [20]. However, whereas curing hypoglycaemia in insulinoma fully reverses all the abnormal responses [20], meticulous prevention of hypoglycaemia in IDDM normalizes the responses of symptoms and onset of cognitive dysfunction, but some neuroendocrine responses improve only to some extent and do not normalize fully.

Why responses of some counterregulatory hormones, namely growth hormone and cortisol, normalize after meticulous prevention of hypoglycaemia, whereas those of adrenaline and pancreatic polypeptide do not, is not clear. However, it should be noted that recovery of responses was inversely correlated with duration of diabetes (Figs 8 and 9). Nearly normal responses were recovered in patients with a few years of diabetes duration, as recently reported [24], whereas patients with more than 15 years duration of diabetes had progressively less recovery of adrenaline (both glycaemic thresholds and maximal responses) and pancreatic polypeptide (glycaemic thresholds) [Figs. 8 and 9]. Although our IDDM patients were free of clinically overt autonomic neuropathy, it cannot be excluded that the patients with longterm IDDM were affected by a subclinical form of autonomic neuropathy, not revealed by the standard cardiovascular tests [26]. An alternative possibility is adrenomedullary insufficiency related to diabetes itself [4]. The latter hypothesis, however, would not account for lack of full recovery of responses of pancreatic polypeptide.
Although patients with long-term IDDM recovered only partial, if any, adrenaline and pancreatic polypeptide responses, they largely recovered autonomic symptoms not only in the experimental stepped hypoglycaemic clamp, but also during hypoglycaemic episodes in their everyday life. This is a new clinical finding which indicates that adrenaline secretion is not the only factor for generation of autonomic symptoms [42], as previously reported in adrenalectomized subjects [43]. In addition, patients with deficient adrenaline responses are supersensitive to minimal increases in plasma adrenaline concentrations [44].

The results of the present studies of large recovery of adrenaline responses to hypoglycaemia in IDDM of short but not long-term IDDM, may help to reconcile the apparently contradictory findings of two recent studies $[40,45]$ in which recovery of adrenaline did [40], or did not occur [45] despite the fact that recovery of symptom responses was comparable in the both studies after prevention of hypoglycaemia. In fact, it appears that diabetes duration was greater in the study in which adrenaline did not recover [45] as compared to the study in which it did [40].

An interesting finding from the present studies was the improved maximal response of glucagon to hypoglycaemia observed after 1 year of meticulous prevention of hypoglycaemia. That at least some of the function of the pancreatic alpha cell was restored after long-term prevention of hypoglycaemia, indicates that the central mechanisms are involved, at least in part, in the pathogenesis of loss of glucagon response to hypoglycaemia $[46,47]$ as they are in the release of anteropituitary hormones, adrenomedullary adrenaline, acetylcholine (e.g., sweating) and pancreatic polypeptide. However, the fact that responses of glucagon to hypoglycaemia improved by only $\sim 20 \%$ in contrast with the several-fold increase in the other counterregulatory hormones, suggests that the pathogenesis of loss of glucagon responses to hypoglycaemia is more complex than that of other counterregulatory hormones, probably as a consequence of an intrinsic alpha-cell defect [46]. Nevertheless, the finding of partial recovery of glucagon to hypoglycaemia after prevention of recurrent hypoglycaemia in long-term IDDM, adds to the recently reported improvement in glucagon responses after only 3 months in short-term diabetes [24]. Note, in the present study the improvements in plasma glucagon responses to hypoglycaemia were observed at plasma insulin concentrations of $\sim 1000$ $\mathrm{pmol} / 1$, i.e., values 3-4 times greater than those observed after s.c. insulin injection in IDDM [48]. Because hyperinsulinaemia suppresses the response of glucagon [49-51], it is likely that in our study the improvement in glucagon responses after meticulous prevention of hypoglycaemia was in fact underestimated. 
Although in the present studies no specific test for adequacy of glucose counterregulation [4-6] was performed, the earlier and greater neuroendocrine responses observed after meticulous prevention of hypoglycaemia in IDDM patients resulted in a more efficient counterregulation of hypoglycaemia. In fact, the rates of glucose infusion required to maintain the hypoglycaemic plateaus between 180$360 \mathrm{~min}$ in the stepped clamp, were lower after prevention of hypoglycaemia, most likely as a result of recovered responses of counterregulatory hormones (Fig. 7).

The recently reported European $[9,10]$ and North American [8] trials have definitively proven the key role of hyperglycaemia in the pathogenesis of microvascular complications of IDDM, and strongly indicate the need for maintenance of near-normoglycaemia in the long term. A problem common to these studies [8,9], is the three-fold increase in the frequency of severe hypoglycaemia reported in intensively treated IDDM patients. At present, the fear of an increased risk for severe hypoglycaemia might exclude not only IDDM patients with previous history of recurrent, severe hypoglycaemia [52], or impaired counterregulation $[5,6]$, but also potentially suitable candidates from programmes of intensive insulin therapy. If this were the case, a number of IDDM patients would not benefit from the protective effects of good glycaemic control against long-term complications [8-10].

In the present study, a therapeutic strategy primarily aiming at prevention of hypoglycaemia, resulted in long-term values of $\mathrm{HbA}_{1 \mathrm{c}}$ in the order of those proven to protect against onset/progression of microvascular complications in prospective, large-scale trials [8-10], but severe hypoglycaemia (coma or need for external assistance) never occurred and the frequency of mild hypoglycaemia was reduced to only approximately 18 episodes per patient-year.

[Parenthetically, in the present studies a blood glucose of $4 \mathrm{mmol} / \mathrm{l}$ was chosen as cut-off value for clinical hypoglycaemia in IDDM patients because the glycaemic threshold for activation of counterregulation is usually set at $-4 \mathrm{mmol} / 1[20,24,28,30]$. Thus, from a practical point of view, it would be wise for clinicians to consider $4 \mathrm{mmol} / 1$ instead of $3 \mathrm{mmol} / 1$ the blood glucose value below which hypoglycaemia is diagnosed in IDDM]. Thus, the present study indicates that IDDM patients with previous history of severe hypoglycaemia, impaired counterregulation and hypoglycaemia unawareness, should not necessarily be excluded from programmes of intensive insulin therapy aiming at long-term near-normoglycaemia. It is likely that at least three factors contributed to the positive results of these studies. First, the use of a physiological model of insulin delivery [25], namely injections of regular insulin prior to each meal and NPH insulin at bed-time. It is worth mentioning that at entry to the study, hypoglycaemia occurred primarily in the late morning and early night hours as a result of inappropriate hyperinsulinaemia following injections of mixtures of regular and NPH insulin prior to breakfast and dinner. Second, the pre-meal glycaemic targets were approximately $7.2-8.3 \mathrm{mmol} / \mathrm{l}$. In fact, because of the imperfection of the present subcutaneous insulin therapy [53], the aim of strictly normal glycaemic targets may easily result in hypoglycaemia. Third, we believe that the key factor was the continuous education of the patients, and their meticulous co-operation with the therapeutic plan, combined with the doctors' availability of time for frequent visits and telephone conversations.

Although these studies were prospectively directed at assessing the effects of prevention of recurrent hypoglycaemia, it could be proposed that the therapeutic program of intensive insulin therapy used in the present studies, might help to largely prevent onset of hypoglycaemia unawareness and impaired counterregulation, if initiated at the early clinical appearance of IDDM. A question which remains unanswered is whether patients with clinically overt autonomic neuropathy and hypoglycaemia unawareness would benefit from a therapeutic programme of prevention of hypoglycaemia such as the one demonstrated to reverse hypoglycaemia unawareness in such patients.

Finally, our results are relevant to IDDM treatment. Because it is likely that hypoglycaemia unawareness is much more common than generally thought, first, diabetic patients should be routinely screened by asking them about the symptoms they experience which coincide with capillary blood glucose measurements of less than $3 \mathrm{mmol} / \mathrm{h}$, especially if $\% \mathrm{HbA}_{1 \mathrm{c}}$ is close to, or within the normal non-diabetic range. Second, day and night blood glucose monitoring should be intensified for several days to establish the frequency of mild-moderate, unrecognized hypoglycaemia. Finally, third, a therapeutic plan like the one described here may be initiated to protect the patients from the risks of hypoglycaemia unawareness, impaired counterregulation and ultimately severe hypoglycaemia.

The long-term results of the strategy of intensive insulin therapy used in these studies speak against the present, somewhat manichean view that in IDDM long-term near-normoglycaemia necessarily begets increased frequency of (severe) hypoglycaemia $[8,9]$. A carefully planned and conducted intensive insulin therapy maintains the $\% \mathrm{HbA}_{1 c}$ in the therapeutic range of protection against complications, and at the same time decreases, rather than increases the frequency of hypoglycaemia, as the present studies demonstrate. Thus, it is possible to extend intensive insulin therapy to the generality of IDDM patients in whom it is desirable to prevent or delay the onset or progression of microvascular com- 
plications at virtually no risk for severe hypoglycaemia, and at only low risk of mild-moderate hypoglycaemia. However, such a goal may be achieved only with a time-consuming, demanding and expensive programme like the one used here, i.e., education of patients by educated doctors.

Acknowledgements. The authors express their deepest gratitude to the IDDM patients who volunteered for the study. Their great enthusiasm, perseverance, co-operation and faith in the hypotheses to be tested, was the key to the positive outcome of the research plan. We are happy that their participation greatly improved their quality of life, which had previously been hampered by recurrent and severe hypoglycaemia. The dedicated editorial help of Ms. P. Boyce, the superb technical assistance of G. Cipiciani, and the friendiy support from the communities of the Nuvolau, Belluno, and the Marmara, Istanbul (FP312), are gratefully acknowledged. This work was presented in part at the 29th Meeting of the European Association of the Study of Diabetes, Istanbul, September 1993. This work was supported by grant 93.00352.PF40 for C.N.R.'s finalized project on aging, and by the Juvenile Diabetes Foundation grant 193108.

\section{References}

1. Gerich J, Mokan M, Veneman T, Korytkowski M, Mitrakou A (1991) Hypoglycemia unawareness. Endo Rev 12: 356371

2. Hepburn D, Patrick A, Eadington D, Ewing D, Frier B (1990) Chawareness of hypoglycemia in insulin-treated diabetic patients: prevalence and relationship to autonomic neuropathy. Diabet Med 7: 711

3. Mokan M, Mitrakou A, Veneman T et al. (in press) Hypoglycemia unawareness in insulin-dependent diabetes mellitus. Diabetes Care (in press)

4. Dagogo-Jack SE, Cryer PE (1993) Hypoglycemia-associated autonomic failure in insulin-dependent diabetes mellitus. Recent antecedent hypoglycemia reduces autonomic responses to, symptoms of, and defense against subsequent hypoglycemia. J Clin Invest 91: 819

5. White N, Skor D, Cryer P et al. (1983) Identification of type 1 diabetic patients at increased risk for hypoglycemia during intensive therapy. $\mathrm{N}$ Engl J Med 308: 485491

6. Bolli G, De Feo P, De Cosmo S et al. (1984) A reliable and reproducible test for adequate glucose counterregulation in type 1 diabetes mellitus. Diabetes 33: 732-737

7. Cryer P, Gerich J (1985) Glucose counterregulation, hypoglycemia, and intensive insulin therapy in diabetes mellitus. N Engl J Med 313: 232-241

8. The Diabetes Control and Complications Trial Research Group (1993) The effect of intensive treatment of diabetes on the development and progression of long-term complications in insulin-dependent diabetes mellitus. N Engl J Med 329: 977-986

9. Reichard P, Nilsson B-Y, Rosenquist U (1993) The effect of long-term intensified insulin treatment on the development of microvascular complications of diabetes mellitus. N Engl J Med 329: 304-309

10. Brinchmann-Hansen O, Dahl-Jorgensen K, Sandvik L, Hanssen K (1992) Blood glucose concentrations and progression of diabetic retinopathy: the seven year results of the Oslo study. BMJ 304: 19-22
11. Heller S, Herbert M, MacDonald I, Tattersall R (1987) Influence of sympathetic nervous system on hypoglycemic warning symptoms. Lancet II: 359-363

12. Amiel S, Sherwin R, Simonson R et al. (1988) Effect of intensive insulin therapy on glycemic thresholds for counterregulatory hormone release. Diabetes 37: 901-907

13. Cryer PE (1992) Iatrogenic hypoglycemia as a cause of hypoglycemia-associated autonomic failure in IDDM. A vicious circle. Diabetes 41: 255-260

14. Heller S, Cryer P (1991) Reduced neuroendocrine and symptomatic responses to subsequent hypoglycemia after one episode of hypoglycemia in nondiabetic humans. Diabetes 40: $223-226$

15. Davis M, Shamoon H (1991) Counterregulatory adaptation to recurrent hypoglycemia in normal humans. $J$ Clin Endocrinol Metab 73: 995-1001

16. Veneman T, Mitrakou A, Mokan M, Cryer P, Gerich J (1993) Induction of hypoglycemia unawareness by asymptomatic nocturnal hypoglycemia. Diabetes 42: 1233-1237

17. Widom B, Simonson DC (1992) Intermittent hypoglycemia impairs glucose counterregulation. Diabetes 41: 1597-1602

18. Lingefelser T, Renn W, Sommerwerck U et al. (1993) Compromised hormonal counterregulation, symptom awareness, and neurophysiological function after recurrent short-term episodes of insulin-induced hypoglycemia in IDDM patients. Diabetes 42: 610-618

19. Maran A, Taylor J, MacDonald I, Amiel S (1992) Evidence for reversibility of defective counterregulation in a patient with insulinoma. Diabet Med 9: 765-768

20. Mitrakou A, Fanelli C, Veneman Tet al. (1993) Reversibility of unawareness of hypoglycemia in patients with insulinomas. N Engl J Med 329: 834-839

21. Lingefelser T, Renn W, Eggstein M, Reinauer M (1993) Restoration of impaired counterregulatory hormone response, symptom perception and cerebral function by short-term euglycemia in IDDM. Diabetes 42: 243A (Abstract)

22. Liu D, McManus R, Toth E, Ryan E (1993) Improved hormonal and symptomatic responses to hypoglycemia in IDDM patients after three months of less strict glucose control. Diabetes 42: 17A (Abstract)

23. Davis M, Mellman M, Friedman S, Shamoon H (1993) Enhanced epinephrine responses during hypoglycemia in IDDM patients on conventional therapy following intensive insulin therapy. Diabetes 42: 80A (Abstract)

24. Fanelli C, Epifano L, Rambotti AM et al. (1993) Meticulous prevention of hypoglycemia (near-)normalizes magnitude and glycemic thresholds of neuroendocrine responses to, symptoms of, and cognitive function during hypoglycemia in intensively treated patients with IDDM of short duration. Diabetes 42: 1683-1689

25. Bolli GB, Perriello G, Fanelli C, De Feo P (1993) Nocturnal blood glucose control in type 1 diabetes mellitus. Diabetes Care 16 [Suppl 1]: 71-89

26. Ewing DJ, Clarke BF (1982) Diagnosis and management of diabetic autonomic neuropathy. BMJ 285: 916-918

27. Mitrakou A, Ryan C, Veneman Tet al. (1991) Hierarchy of glycemic thresholds for counterregulatory hormone secretion, symptoms, and cerebral dysfunction. Am J Physiol 260: E67-E74

28. Fanelli C, Modarelli F, Rambotti AM et al. (1994) Relative roles of insulin and hypoglycaemia on induction of neuroendocrine responses to, symptoms of, and deterioration of cognitive function in, hypoglycaemia in humans. Diabetologia 37: 797-807

29. Perriello G, Torlone E, Di Santo S et al. (1988) Effects of storage temperature of insulin on pharmacokinetics and 
pharmacodynamics of insulin mixtures injected subcutaneously in subjects with IDDM. Diabetologia 31: 811-815

30. Schwartz N, Clutter W, Shah S, Cryer P (1987) Glycemic thresholds for activation of glucose counterregulatory systems are higher than the thresholds for symptoms. J Clin Invest 79: 777-781

31. Fanelli C, De Feo P, Porcellati F et al. (1992) Adrenergic mechanisms contribute to the late phase of hypoglycemic glucose counterregulation in humans by stimulating lipolysis. J Clin Invest 89: 2005-2013

32. Kohn A, Annibale B, Suriano G et al. (1985) Gastric acid and pancreatic polypeptide responses to modified sham feeding: indication of an increased basal vagal tone in a subgroup of duodenal ulcer patients. Gut 26: 776-782

33. Zar J (1984) Biostatistical analysis. Prentice Hall, Englewood Cliffs

34. McCall A, Fixman L, Fleming N et al. (1986) Chronic hypoglycemia increases brain glucose transport. Am J Physiol 251: E442-E447

35. Boyle PJ, Nagy R, O'Connor AM et al. (in press) Adaptation in brain glucose uptake following recurrent hypoglycemia. Proc Natl Acad Sci USA (in press)

36. Boyle P, Schwartz N, Shah S, Clutter W, Cryer P (1988) Plasma glucose concentrations at the onset of hypoglycemic symptoms in patients with poorly controlled diabetes and in nondiabetics. N Engl J Med 318: 1487-1492

37. De Feo P, Gallai V, Mazzotta G, et al. (1988) Modest decrements in plasma glucose concentration cause early impairment in cognitive function and later activation of glucose counterregulation in the absence of hypoglycemic symptoms in normal man. J Clin Invest 82: 436-434

38. Widom B, Simonson DC (1990) Glycemic control and neuropsychologic function during hypoglycemia in patients with insulin-dependent diabetes mellitus. Ann Intern Med 112: 904-912

39. Maran A, Lomas J, MacDonald I, Amiel S (1993) Lack of protection of cerebral function in well controlled diabetic patients with hypoglycemia unawareness. Diabetes 42: 17A (Abstract)

40. Cranston I, Lomas J, Maran A, Macdonald I, Amiel SA (1994) Restoration of hypoglycaemia awareness in patients with long-duration insulin-dependent diabetes. Lancet 344: 283-287

41. Clarke WL, Gonder-Frederick LA, Richards FE, Cryer PE (1991) Multifactorial origin of hypoglycemia unawareness in IDDM: association with defective glucose counterregulation and better glycemic control. Diabetes 40: 680-685

42. Heller S, McDonald I (1991) Physiological disturbances in hypoglycaemia: effect on subjective awareness. Clin Sci 81: $1-9$

43. Ginsburg J, Paton A (1956) Effects of insulin after adrenalectomy. Lancet 2: 491-494

44. Hilsted J, Richter E, Madsbad S et al. (1987) Metabolic and cardiovascular responses to epinephrine in diabetic autonomic neuropathy. N Engl J Med 317: 421-426

45. Dagogo-Jack S, Rattarasarn C, Cryer P Reversal of hypoglycemia unawareness, but not glucose counterregulation, in insulin dependent diabetes mellitus. Diabetes (in press)

46. Gerich J, Langlois M, Noacco C et al. (1973) Lack of glucagon response to hypoglycemia in diabetes: evidence for an intrinsic pancreatic alpha-cell defect. Science 182: 171173

47. Bolli GB, De Feo P, Compagnucci P et al. (1983) Abnormal glucose counterregulation in insulin-dependent diabetes mellitus. Interaction of anti-insulin antibodies and impaired glucagon and epinephrine secretion. Diabetes 32: 134-141

48. Bolli G, Dimitriadis G, Pehling G et al. (1984) Abnormal glucose counterregulation after subcutaneous insulin in insulin-dependent diabetes mellitus. N Engl J Med 310: $1706-1711$

49. Diamond M, Hallarman L, Starick-Zych K et al. (1991) Suppression of counterregulatory hormone response to hypoglycemia by insulin per se. J Clin Endocrinol Metab 72: $1388-1390$

50. Liu D, Moberg E, Kollind M, Lins P-E, Adamson U (1991) A high concentration of insulin suppresses the glucagon response to hypoglycemia in man. J Clin Endocrinol Metab 73: $1123-1128$

51. Liu D, Adamson U, Lins P-E, et al. (1992) Inhibitory effect of circulating insulin on glucagon secretion during hypoglycaemia in type I diabetes. Diabetes Care 15: 59-65

52. The DCCT Research Group (1991) Epidemiology of severe hypoglycemia in the Diabetes Control and Complications Trial. Am J Med 90: 450-459

53. Binder C, Lauritzen T, Faber O, Pramming O (1984) Insulin pharmacokinetics. Diabetes Care 3: 188-199 